\title{
Optimization of Fenton's oxidation of herbicide dicamba in water using response surface methodology
}

\author{
Sanjeev Sangami ${ }^{1} \cdot$ Basavaraju Manu $^{1}$
}

Received: 6 February 2017/ Accepted: 3 April 2017/Published online: 10 April 2017

(c) The Author(s) 2017. This article is an open access publication

\begin{abstract}
In this study Fenton's oxidation of dicamba in aqueous medium was investigated by using the response surface methodology. The influence of $\mathrm{H}_{2} \mathrm{O}_{2} / \mathrm{COD}(A)$, $\mathrm{H}_{2} \mathrm{O}_{2} / \mathrm{Fe}^{2+}(B), \mathrm{pH}(C)$ and reaction time $(D)$ as independent variables were studied on two responses (COD and dicamba removal efficiency). The dosage of $\mathrm{H}_{2} \mathrm{O}_{2}$ $(5.35-17.4 \mathrm{mM})$ and $\mathrm{Fe}^{2+}(0.09-2.13 \mathrm{mM})$ were varied and optimum percentage removal of dicamba of $84.01 \%$ with $\mathrm{H}_{2} \mathrm{O}_{2}$ and $\mathrm{Fe}^{2+}$ dosage of 11.38 and $0.33 \mathrm{mM}$ respectively. The whole oxidation process was monitored by high performance liquid chromatography (HPLC) along with liquid chromatography/mass spectrometry (LC/MS). It was found that $82 \%$ of dicamba was mineralized to oxalic acid, chloride ion, $\mathrm{CO}_{2}$ and $\mathrm{H}_{2} \mathrm{O}$, which was confirmed with COD removal of $81.53 \%$. The regression analysis was performed, in which standard deviation $(<4 \%)$, coefficient of variation $(<8), F$ value (Fisher's Test) (>2.74), coefficient of correlation $\left(R^{2}=R_{\text {adj }}^{2}\right)$ and adequate precision $(>12)$ were in good agreement with model values. Finally, the treatment process was validated by performing the additional experiments.
\end{abstract}

Electronic supplementary material The online version of this article (doi:10.1007/s13201-017-0559-8) contains supplementary material, which is available to authorized users.

Sanjeev Sangami

sanjeevenv08@gmail.com

Basavaraju Manu

bmanu@nitk.ac.in

1 Department of Civil Engineering, National Institute of Technology Karnataka, Surathkal, P.O. Srinivasnagar (D.K), Mangalore 575025, India
Keywords Dicamba $\cdot$ Fenton's process - Response surface methodology $\cdot$ Herbicide $\cdot$ Agriculture runoff

\section{Introduction}

Dicamba (3,6-dichloro-2-methoxy benzoic acid) is widely used as a post-emergency herbicide to control the broadleaf weeds present in agriculture field (González et al. 2006). It is also used in industrial sites, railway embankments and gardens to remove the unwanted plants. This herbicide is mainly applied for weed control, however the application does not ensure that it is safe for main crop such as sugarcane, maize etc. It was also true that very less amount is utilized by the targeted plants and major portion is retained in the soil itself (Jiang et al. 2008). As a result, during the heavy rainfall the residues present in the soil can easily enter into the water body and thereby causing water pollution. The accumulation of this herbicide is mainly dependent on water solubility $(4500 \mathrm{mg} / \mathrm{L})$, mobility, half life (28.3 days) and other soil-water characteristics (Ghoshdastidar and Tong 2013). Therefore, more deposition of this herbicide was observed in surface water than ground water and it was also said that, the herbicides are the most frequently detected pesticides in aqueous environments (Catalkaya and Kargi 2009). The physicochemical properties of this herbicide were listed in Table 1. Dicamba is having a toxic effect on aquatic life, animals and human beings (Shin et al. 2011). The US EPA (United States Environmental Protection Agency) has recommended $200 \mu \mathrm{g} \mathrm{L}^{-1}$ as a standard limit in drinking water (Hamilton et al. 2003). Therefore, the proper treatment technology is needed to reduce toxicity levels of dicamba in water. 
Table 1 Physical and chemical properties of dicamba

\begin{tabular}{ll}
\hline Properties & Dicamba \\
\hline Structure & \\
& \\
Synonym & $3,6-\mathrm{Dichloro}-2-\mathrm{methoxybenzoic} \mathrm{acid}$ \\
Appearance & $\mathrm{White} \mathrm{powder}_{\text {M.W (molecular weight) }} 221.00 \mathrm{~g} / \mathrm{mol}^{-}$ \\
Chemical formula & $\mathrm{C}_{6} \mathrm{H}_{2} \mathrm{Cl}_{2}(\mathrm{OCH}) \mathrm{CO}_{2} \mathrm{H}$ \\
Water solubility (mg/L) & 4500 at $25{ }^{\circ} \mathrm{C}$ \\
M. P and B P & 115 and $200{ }^{\circ} \mathrm{C}$ \\
Density (g/cc) & 1.18 \\
\hline
\end{tabular}

Now a days the advanced oxidation processes (AOPs) are becoming more popular in treatment of herbicides containing water. Among all the AOPs, the Fenton's process is cost effective and it generates $\mathrm{OH}$ radical (oxidation potential $=2.8 \mathrm{~V}$ ) by reacting with $\mathrm{Fe}^{2+}$ and $\mathrm{H}_{2} \mathrm{O}_{2}$ (Wang and Lemley 2001, 2003). The $\mathrm{OH}$ radical reacts with pollutant and forms degradation products (transformation products) or mineralization products $\left(\mathrm{CO}_{2}, \mathrm{H}_{2} \mathrm{O}\right.$, mineral acids) or sometimes both are formed, shown in Eqs. (1, 2, 3):

$$
\begin{aligned}
& \mathrm{H}_{2} \mathrm{O}_{2}+\mathrm{Fe}^{2+} \rightarrow \mathrm{OH}+\mathrm{OH}^{-}+\mathrm{Fe}^{3+}, \\
& \mathrm{H}_{2} \mathrm{O}_{2}+\mathrm{Fe}^{3+} \rightarrow \mathrm{OOH}+\mathrm{H}^{+}+\mathrm{Fe}^{2+}, \\
& \mathrm{OH}+\text { Organics } \rightarrow \text { Products. }
\end{aligned}
$$

Many researchers were successfully applied the AOPs in degradation of dicamba in water, which includes photocatalytic oxidation ( $\mathrm{Lu}$ and Chen 1997), anodic oxidation, electro-Fenton followed by photoelectroFenton (Brillas et al. 2003), $\mathrm{Zno}-\mathrm{Fe}_{2} \mathrm{O}_{3}$ catalyst (MayaTreviñoa et al. 2014). Also, the physical and biological methods have been applied, which includes adsorption with calcined-layered double hydroxide (You et al. 2002) membrane bioreactor (Ghoshdastidar and Tong 2013) and activated sludge process (Nitschke et al. 1999). However, biological methods are more resistant towards the microbial degradation and require a lot of time for complete degradation. Surprisingly, so far very less studies are available for the oxidative degradation of dicamba using Fenton's process and it was proved that it is the most effective and economical method in all the AOPs (Chu et al. 2012).

The efficiency of this treatment method depends on the dosage of iron, $\mathrm{H}_{2} \mathrm{O}_{2}$, $\mathrm{pH}$, reaction time, mixing speed and pollutant concentration. The effect of all these factors on performance of Fenton's reagent was systematically studied using response surface methodology (RSM) than conventional method [one-variable-at a-time (OVAT)]. This OVAT is expensive, consumes more time and chemicals and doesn't give any significant interactions between the factors. The RSM involves only a few sets of experiments with a wide range of values and gives the best fit model, where the optimal response occurs (Ahmadi et al. 2005; Myers and Montgomery 2002). Hence, this experimental design was applied by many of the researchers in Fenton's process (Zhang et al. 2009; Masomboon et al. 2010; Colombo et al. 2013). Here, the CCD (central composite design) type of RSM was considered, which is flexible, efficient, measures experimental errors accurately and it work under both region of interest and operatablity (Ahmad et al. 2005). Therefore, the main aim is to study the efficiency of Fenton's reagent for the degradation of dicamba in aqueous medium. The effect of several factors $\left(\mathrm{H}_{2} \mathrm{O}_{2} / \mathrm{COD}, \mathrm{H}_{2} \mathrm{O}_{2} / \mathrm{Fe}^{2+}, \mathrm{pH}\right.$, and reaction time) was studied on responses (\% COD and \% dicamba removal efficiency) by applying the response surface methodology.

\section{Materials and methods}

\section{Reagents}

All the reagents are of analytical grade obtained from Merck manufactured in India, which includes hydrogen peroxide $\left(\mathrm{H}_{2} \mathrm{O}_{2}, 30 \% \mathrm{w} / \mathrm{w}\right), \mathrm{HCl}(35 \%)$, sulfuric acid (98-99\%), sodium hydroxide, potassium iodide (KI), mercuric sulfate $\left(\mathrm{HgSO}_{4}\right)$, potassium dichromate $\left(\mathrm{K}_{2} \mathrm{Cr}_{2} \mathrm{O}_{7}\right)$, silver sulfate $\left(\mathrm{Ag}_{2} \mathrm{SO}_{4}\right)$, ferrous (II) sulfate heptahydrate $\left(\mathrm{FeSO}_{4} \cdot 7 \mathrm{H} 2 \mathrm{O}\right)$, FAS (ferrous ammonium sulfate), ferroin indicator, starch, sodium thiosulfate $\left(\mathrm{Na}_{2-}\right.$ $\mathrm{S}_{2} \mathrm{O}_{3}$ ), ultra Pure water, methanol (HPLC grade). The dicamba was procured from Sigma Aldrich (99\% pure).

\section{Experimental methodology}

The $3 \mathrm{mM}$ dicamba stock solution and the working standard solutions of $0.13-0.65 \mathrm{mM}$ were prepared using ultra pure water. All the standards $(0.13-0.65 \mathrm{mM})$ were analyzed by high performance liquid chromatography (HPLC) and finally the calibration curve was prepared. The initial concentration of dicamba was selected by considering the agriculture runoff water characteristics collected from the study area (0.5 acres of sugarcane field) at Veerapur, Belgaum District in Karnataka state (Latitude: $15^{\circ} 41^{\prime} 27.64^{\prime \prime} \mathrm{N}$; Longitude: $74^{\circ} 39^{\prime} 9.11^{\prime \prime} \mathrm{E}$ ). In the runoff water the dicamba concentration was found to be $93.7 \mathrm{mg} /$ L. Therefore, $0.39 \mathrm{mM}(86.19 \mathrm{mg} / \mathrm{L})$ dicamba was selected 
as initial concentration, which is near to the observed value in the field.

The batch studies were conducted in $500 \mathrm{~mL}$ Erlenmeyer flask with sample size $250 \mathrm{~mL}$ at room temperatures (29-31 ${ }^{\circ} \mathrm{C}$ ) and atmospheric pressure with continuous mixing of $210 \mathrm{rpm}$. Total 26 experiments (runs) were conducted according to the RSM design matrix and each run was performed in triplicate and an average of three values was considered. The aqueous solution $\mathrm{pH}$ from 2 to 5 was adjusted with $0.1 \mathrm{~N} \mathrm{H}_{2} \mathrm{SO}_{4}$. Then, the designed dose of iron as $\mathrm{Fe}^{2+}(0.09-2.13 \mathrm{mM})$ and hydrogen peroxide (5.35-17.4 mM) were added and Fenton's reaction was initiated. After each designed reaction time (30-240 $\mathrm{min}$ ), the treated sample was dispensed into a glass cylinder and filtered through $0.2 \mu$ filter paper. Then, the final concentration of dicamba was measured with HPLC calibration curve and degradation products were analyzed with LC/MS (liquid chromatography/mass spectrometry). The final COD, residual hydrogen peroxide, residual iron, residual chloride and final $\mathrm{pH}$ were also measured. The $\mathrm{H}_{2} \mathrm{O}_{2}$ interference in COD is corrected according to the method given in the literature (Wu and Englehardt 2012) and the COD removal efficiency was calculated with Eq. (4). Initially the blank experiment was carryout for $24 \mathrm{~h}$ without adding any reagents, no significant removal was observed:

$\mathrm{COD}$ removal efficiency $=\left(\mathrm{COD}_{\mathrm{i}}-\mathrm{COD}_{\mathrm{f}}\right) / \mathrm{COD}_{\mathrm{i}}$,

where $\mathrm{COD}_{\mathrm{i}}$ is the initial COD $(\mathrm{mg} / \mathrm{L})$ and $\mathrm{COD}_{\mathrm{f}}(\mathrm{mg} / \mathrm{L})$ is its final COD after designed reaction time.

\section{Analytical procedure}

The degradation of dicamba was measured with the HPLC (Agilent 1260) by applying proper conditions. The HPLC consists of RP-C18 column with size $100 \times 4.6 \mathrm{~mm}, 3.5 \mu$ pore size, temperature $25^{\circ} \mathrm{C}$, binary pump with $1 \mathrm{~mL} / \mathrm{min}$ of flow rate, mobile phase: methanol: water (50:50), sample volume of $20 \mu \mathrm{L}$ and a diode array detector (DAD). The retention time was found to be at $1.382 \mathrm{~min}$. The mineralized products were analyzed by LC/MS-2020 (Shimadzu) with single quadrupole having a $\mathrm{C}-18$ column. The chemical oxygen demand (COD) was measured using the closed reflux titration method (American Public Health Association (APHA) et al. 2005). The $\lambda_{\max }$ value of dicamba and residual iron as $\mathrm{Fe}^{3+}$ (potassium thiocynate method) of the effluent was measured using ultra-violet visible (UV-Vis) double beam spectrophotometer (Systronics, AU-2701). The initial and final $\mathrm{pH}$ was monitored using a $\mathrm{pH}$ meter (Systronics). Before and after treatment the chloride ion was measured by titrating with silver nitrate. The iodometric titration was used to find out the residual hydrogen peroxide in a treated sample.

\section{Experimental design}

Initially the RSM was proposed by Box and Wilson in 1951 with first-degree polynomial model and later it was improved to three levels of second-order model (Box and Behnken 1960; Box and Wilson 1951), now it is possible to perform in five levels also. The central composite design (CCD) is one of the more popular method in RSM and it efficiently estimates the first and second-order terms in quadratic model equation. The CCD can be designed in both three levels $(-1,0,+1$,$) and five levels (-\alpha,-1,0,1$, and $+\alpha$ ). Here, the value of $\alpha$ is calculated with Eq. (5), which is based on rotatability and orthogonality of blocks. Suppose, if the number of factors are 2, with 2 trail runs, then $\alpha$ value is calculated as $2^{2 / 4}=1.414$. It has mainly factorial, axial (star points) and center points. In the present study, total 26 experiments $(N)$ were conducted according to Eq. (6) (Tiwari et al. 2008) with $\alpha=1$ and the center point is repeated two times for the consistency of the results:

$$
\begin{aligned}
\alpha= & {[\text { number of factorial runs }]^{1 / 4}, } \\
N= & \text { factorial points }\left(2^{k}\right)+\text { axial points }(2 * k) \\
& + \text { center points } \\
= & 2^{4}+(2 * 4)+2=26 .
\end{aligned}
$$

The influence of independent factors such as $\mathrm{H}_{2} \mathrm{O}_{2} / \mathrm{COD}$ $\left(X_{1}\right), \mathrm{H}_{2} \mathrm{O}_{2} / \mathrm{Fe}^{2+}\left(X_{2}\right) \mathrm{pH}\left(X_{3}\right)$ and reaction time $\left(X_{4}\right)$ was studied on two dependent variables such as \% COD removal efficiency $\left(Y_{1}\right)$ and \% dicamba removal efficiency $\left(Y_{2}\right)$. The independent variables $\left(X_{1}, X_{2}, X_{3}\right.$ and $\left.X_{4}\right)$ are calculated with Eq. (7) (Zhang et al. 2010), where, $X_{0}$ is $X_{i}$ value at the middle point and $X_{\mathrm{D}}$ is the step change (difference/2), $x_{i}$ is the coded value of $i$ th factor. The interactive effect between dependent and independent variables was expressed as a second order polynomial Eq. (8):

$x_{i}=\left(\left(X_{i}-X_{0}\right) / X_{D}\right) \quad i=1,2,3 \ldots k$,

$Y=b_{0}+\sum_{i=1}^{k} b_{i} X_{i}+\sum_{i=1}^{k} b_{i i} X_{i}^{2}+\sum_{i=1}^{k} \sum_{j=1}^{k} b_{i j} X_{i} X_{j}$

where $Y$ is the dependent variable and $X_{i}, X_{j}$ are considered as independent variables or control variables and for convenience, all these variables are assigned as $A, B, C$ and $D$ for $X_{1}, X_{2}, X_{3}$ and $X_{4}$ respectively. The $b_{0}$ (constant or intercept), $b_{i}$ (linear term), $b_{i i}$ (quadratic term) and $b_{i j}$ (second order terms) are the coefficients and $k$ is the number of control variables (Bashir et al. 2009). The response surface analysis was performed using Minitab software (version 17).

In Fenton's process, the $\mathrm{H}_{2} \mathrm{O}_{2}$ dosage was decided based on the theoretical oxidant required to degrade the dicamba in synthetic solution. Therefore, the COD value of a dicamba was taken as a reference and the middle value of $\mathrm{H}_{2} \mathrm{O}_{2} / \mathrm{COD}$ ratio was considered as the 2.125 (theoretical 
Table 2 Levels of the parameters studied in the CCD

\begin{tabular}{lllll}
\hline Factor & Name & Low $(-1)$ & Middle (0) & High $(+1)$ \\
\hline$A\left(X_{1}\right)$ & $\mathrm{H}_{2} \mathrm{O}_{2} / \mathrm{COD}$ & 1 & 2.125 & 3.5 \\
$B\left(X_{2}\right)$ & $\mathrm{H}_{2} \mathrm{O}_{2} / \mathrm{Fe}^{2+}$ & 5 & 21 & 37 \\
$C\left(X_{3}\right)$ & $\mathrm{PH}$ & 2 & 3.5 & 5 \\
$D\left(X_{4}\right)$ & Time (min) & 30 & 135 & 240 \\
\hline
\end{tabular}

relation), in which the maximum number of $\mathrm{OH}$ radicals are produced (Kim et al. 1997) and the value is near to 2.15 in the previous literature (Kavitha and Palanivelu 2004). Hence, these values were selected as 1, 2.125 and 3.25. In many of the literatures, the ratio of $\mathrm{H}_{2} \mathrm{O}_{2} / \mathrm{Fe}^{2+}$ was reported as 9.5 (Torrades et al. 2011), 50 (Martins et al. 2010) and 165 (Manu and Mahamood 2011). It was also evident that, this ratio was depending on the nature of the compound (Mater et al. 2007). Hence, in this present study the $\mathrm{H}_{2} \mathrm{O}_{2} / \mathrm{Fe}^{2+}$ ratios are selected as 5, 21 and 37. Here, the ratios are based on mass (molar) and it was reported in many of the researchers (Bach et al. 2010; Hasan et al. 2012). It was proved that, the Fenton's oxidation shows better results in acidic pH from 2 to 5 (Xu et al. 2004; Saber et al. 2014) and 3-4 (Lucas et al. 2007; Manu and Mahamood 2011). Hence, the $\mathrm{pH}$ values were considered as $2,3.5$ and 5 . The range of reaction time was selected as 30-240 by considering the evidences from other researchers as 60-240 min (Martins et al. 2010), 30-240 min (Hasan et al. 2012) and 120-360 min (Li et al. 2010). All these values are listed in Table 2.

ANOVA (analysis of variance) was applied to interpret the complex relationship between the variables involved in Fenton's process. The coefficient of determination $\left(R^{2}\right)$, Fisher's test $(F$ test) and the probability $(P)$ value at its 95\% confidence level were used to study the performance of the second order polynomial equation (García-Ǵomez et al. 2016). The 3D surface and contour plots were studied to know the significant interactions between the responses and control factors.

\section{Results and discussion}

The values of both dependent (observed and predicted) and independent variables are shown in Table 3. The ANOVA results of two responses are presented in Tables 4 and 5 .

\section{Central composite design model and statistical analysis}

The response functions along with interaction coefficients of independent variables are presented by Eqs. $(9,10)$. Both the equations involve one constant term, four linear terms $(A, B$,
$C, D)$, four quadratic terms $\left(A^{*} A, B^{*} B, C^{*} C, D^{*} D\right)$ and six interaction terms $\left(A^{*} B, A^{*} C, A^{*} D, B^{*} C, B^{*} D, C^{*} D\right)$.

$$
\begin{aligned}
\% \operatorname{COD} R\left(Y_{1}\right)= & 65.64-0.44 A+1.52 B+0.98 C \\
& +2.00 D-23.95 A * A-12.51 B * B \\
& -19.11 C * C+16.49 D * D+0.44 A \\
& * B-0.11 A * C+0.99 A * D+2.09 B \\
& * C 0.55 B * D-2.2 B * D,
\end{aligned}
$$

$$
\begin{aligned}
\% D R\left(Y_{2}\right)= & 69.04-0.20 A+0.87 B+1.59 C+2.11 D \\
& -19.80 A * A-16.45 B * B-20.20 C * C \\
& +15.74 D * D-1.08 A * B-1.20 A * C \\
& +1.31 A * D+2.52 B * C-0.07 B * D \\
& -0.69 C * D
\end{aligned}
$$

The intercept values are 65.64 and 69.04 for of COD $\left(Y_{1}\right)$ and dicamba removal $\left(Y_{2}\right)$ respectively, implies that the both responses are showing a positive effect. Along with intercept values, the coefficients of $B, C, D, D^{2}, A^{*} B$, $A^{*} D, B^{*} C$ are also having a positive effect on the \% COD removal and the coefficients of $D^{2}$ has the highest positive value of 16.49 . Hence, the reaction time $(D)$ has more influencing on \% COD removal efficiency (\% COD $R$ ). However, in case \% dicamba removal efficiency the coefficients of $B, C, D, D^{2}, A^{*} D, B^{*} C$ have a positive effect, in which the reaction time $\left(D^{2}\right)$ has greatest positive value of 15.74 . Hence, it can be concluded that the $D^{2}$ has a more positive influence on both responses.

To find out the relation between the mean square (MS) and the residual error of the model, the $F$ test (Fisher's test) analysis was performed. The experimentally calculated $F$ values for both the responses are 9.93 and 7.57 . These values are greater than the tabular value of $F_{0.05(14,11)}=2.74$, this implies that, the Fenton's treatment option was more significant towards the removal of dicamba from aqueous medium. The coefficient of determination $\left(R^{2}\right)$ was calculated, which is the variation between the actual responses and fits (Ahmadi et al. 2005). The $R^{2}$ and $R_{\text {adj }}^{2}$ are depends on the sample size and the number of terms in the model. Usually, if the number of terms in the model are more with less sample size, then $R_{\text {adj }}^{2}<R^{2}$ (Zhang et al. 2012). These values $\left(R^{2}\right.$ and $\left.R_{\text {adj }}^{2}\right)$ were found to be $92.67,90.34$ and $90.59 \%, 88.62$ for $\%$ dicamba and \% COD removal efficiency respectively. Here, it is seen that the variation between $R^{2}$ and $R_{\text {adj }}^{2}$ is less than $2.5 \%$ for both responses and $R_{\text {adj }}^{2}<R^{2}$, which means that the obtained results are best fit with modeled values and the same trend was reported in other literatures also (Santos and Boaventura 2008; Zhang et al. 2012). According to the Joglekar and May in 1987, the minimum $R^{2}$ value should be at least $80 \%$ and hence, in the present 
Table 3 CCD design matrix

\begin{tabular}{|c|c|c|c|c|c|c|c|c|c|c|}
\hline \multirow[t]{2}{*}{ Run } & \multicolumn{4}{|c|}{ Independent variables (uncoded and coded) } & \multicolumn{2}{|c|}{ Fenton's reagent } & \multicolumn{2}{|c|}{ Actual responses } & \multicolumn{2}{|c|}{ Predicted responses } \\
\hline & $A\left(\mathrm{H}_{2} \mathrm{O}_{2} / \mathrm{COD}\right)$ & $B\left(\mathrm{H}_{2} \mathrm{O}_{2} / \mathrm{Fe}^{2+}\right)$ & $C(\mathrm{PH})$ & $D$ (time min) & $\mathrm{H}_{2} \mathrm{O}_{2}(\mathrm{mM})$ & $\mathrm{Fe}^{2+}(\mathrm{mM})$ & $\% D R$ & $\% \operatorname{COD} R$ & $\% D R$ & $\% \operatorname{COD} R$ \\
\hline 1 & $2.125(0)$ & $21(0)$ & $3.5(0)$ & $30(-1)$ & 11.38 & 0.33 & 74.46 & 70.10 & 82.68 & 80.13 \\
\hline 2 & $2.125(0)$ & $37(1)$ & $3.5(0)$ & $135(0)$ & 11.38 & 0.19 & 45.31 & 47.25 & 53.47 & 54.65 \\
\hline 3 & $3.25(1)$ & $5(-1)$ & $5(1)$ & $30(-1)$ & 17.4 & 2.13 & 24.30 & 22.63 & 23.42 & 21.61 \\
\hline 4 & $2.125(0)$ & $21(0)$ & $3.5(0)$ & $135(0)$ & 11.38 & 0.33 & 83.43 & 82.41 & 79.04 & 75.64 \\
\hline 5 & $3.25(1)$ & $37(1)$ & $2(-1)$ & $30(-1)$ & 17.4 & 0.29 & 22.30 & 23.51 & 20.10 & 20.48 \\
\hline 6 & $2.125(0)$ & $21(0)$ & $2(-1)$ & $135(0)$ & 11.38 & 0.33 & 42.10 & 38.46 & 47.26 & 45.56 \\
\hline 7 & $3.25(1)$ & 37 (1) & $5(1)$ & $240(1)$ & 17.4 & 0.29 & 32.30 & 33.18 & 33.49 & 31.28 \\
\hline 8 & 3.25 (1) & $5(-1)$ & $5(1)$ & $240(1)$ & 17.4 & 2.13 & 29.60 & 24.39 & 29.00 & 24.29 \\
\hline 9 & $2.125(0)$ & $21(0)$ & $3.5(0)$ & $135(0)$ & 11.38 & 0.33 & 84.01 & 81.53 & 79.04 & 75.64 \\
\hline 10 & $1(-1)$ & $37(1)$ & $2(-1)$ & $240(1)$ & 5.35 & 0.09 & 27.30 & 29.67 & 26.60 & 27.57 \\
\hline 11 & $1(-1)$ & $21(0)$ & $3.5(0)$ & $135(0)$ & 5.35 & 0.16 & 43.50 & 38.46 & 49.44 & 42.13 \\
\hline 12 & $1(-1)$ & $5(-1)$ & $5(1)$ & $30(-1)$ & 5.35 & 0.66 & 25.60 & 25.27 & 26.67 & 25.57 \\
\hline 13 & $2.125(0)$ & $21(0)$ & $3.5(0)$ & $240(1)$ & 11.38 & 0.33 & 85.33 & 83.29 & 86.89 & 84.14 \\
\hline 14 & $1(-1)$ & $37(1)$ & $5(1)$ & $30(-1)$ & 5.35 & 0.09 & 38.42 & 36.70 & 35.75 & 32.99 \\
\hline 15 & $2.125(0)$ & $21(0)$ & $5(1)$ & $135(0)$ & 11.38 & 0.33 & 45.80 & 43.73 & 50.43 & 47.51 \\
\hline 16 & 3.25 (1) & $5(-1)$ & $2(-1)$ & $240(1)$ & 17.4 & 2.13 & 33.56 & 30.54 & 34.65 & 31.13 \\
\hline 17 & 3.25 (1) & $5(-1)$ & $2(-1)$ & $30(-1)$ & 17.4 & 2.13 & 26.20 & 21.75 & 26.30 & 19.65 \\
\hline 18 & $3.25(1)$ & $37(1)$ & $2(-1)$ & $240(1)$ & 17.4 & 0.29 & 31.00 & 29.67 & 29.06 & 29.77 \\
\hline 19 & $1(-1)$ & $5(-1)$ & $2(-1)$ & $240(1)$ & 5.35 & 0.66 & 27.25 & 30.54 & 27.88 & 30.69 \\
\hline 20 & $1(-1)$ & $5(-1)$ & $5(1)$ & $240(1)$ & 5.35 & 0.66 & 27.30 & 24.39 & 27.03 & 24.30 \\
\hline 21 & $1(-1)$ & $37(1)$ & $5(1)$ & $240(1)$ & 5.35 & 0.09 & 36.78 & 27.03 & 35.82 & 29.53 \\
\hline 22 & $1(-1)$ & $5(-1)$ & $2(-1)$ & $30(-1)$ & 5.35 & 0.66 & 27.52 & 24.39 & 24.75 & 23.17 \\
\hline 23 & $2.125(0)$ & $5(-1)$ & $3.5(0)$ & $135(0)$ & 11.38 & 1.39 & 50.10 & 48.13 & 51.72 & 51.62 \\
\hline 24 & $1(-1)$ & $37(1)$ & $2(-1)$ & $30(-1)$ & 5.35 & 0.09 & 24.03 & 21.75 & 23.76 & 22.25 \\
\hline 25 & $3.25(1)$ & $37(1)$ & $5(1)$ & $30(-1)$ & 17.4 & 0.29 & 29.70 & 30.54 & 28.20 & 30.79 \\
\hline 26 & $3.25(1)$ & $21(0)$ & $3.5(0)$ & $135(0)$ & 17.4 & 0.51 & 45.20 & 34.04 & 49.05 & 41.25 \\
\hline
\end{tabular}

work the actual and predicted responses are compared (Joglekar and May 1987) (Table 3; Fig. 5). And it was observed that $R^{2}$ values are $>80 \%$, implies that the obtained results are quite satisfactory. The pure error (difference between lack of fit and residual error) values are 0.17 and 0.39 for $\%$ dicamba $\left(Y_{2}\right)$ and \% COD removal $\left(Y_{1}\right)$ respectively. It means that, less error was observed between the actual responses and fits. The noise in the responses (variation between experimental and predicted values) was measured with the lack of fit $P$ values and the values were 3.8 and $5.2 \%$ for $Y_{2}$ and $Y_{1}$ respectively, which were less than observed values $(<14.4 \%)$ in the literature (Im et al. 2012). Hence, treatment process was more significant towards both removal efficiencies.

The standard deviation (SD) is the how many values in responses are differing from the mean value and these values are 1.83, 2.06 for $Y_{2}$ and $Y_{1}$ respectively. The coefficient of variation $(\mathrm{CV})$ is the percentage ratio of standard error to the mean value of the response and values are $5.85 \%\left(Y_{2}\right)$ and $6.91 \%\left(Y_{1}\right)$. According to Beg et al.
(2003) the CV values should be less than $10 \%$ and the obtained values less than $10 \%$. The adequate precision (AP) is the ratio of predicted values of the response to its error and the values are $37.5\left(Y_{2}\right)$ and $61.7\left(Y_{1}\right)$ for both responses and the standard value is 4 or $>4$ (Zinatizadeh et al. 2006). The SD, CV and AP values are within the limits, hence the experimentally obtained results are more reliable.

To know the exact pattern of all 26 runs, the graphs are plotted against the all observations in Fig. $1 \mathrm{a}, \mathrm{b}$ and the points are randomly distributed along both positive and negative sides of the straight line and the maximum residual was observed in positive side. Hence, it is a good trend in the treatment process.

\section{Effects of independent variables on the responses}

The ratio of $\mathrm{H}_{2} \mathrm{O}_{2} / \mathrm{COD}$ is very important, which acts as the basis for considering a range of $\mathrm{H}_{2} \mathrm{O}_{2}$ dosages and the values were varied as $1,2.125$ and 3.25 . It is seen that, as 
Table 4 Analysis of variance for $\% \mathrm{DR}$

\begin{tabular}{|c|c|c|c|c|c|}
\hline Source & DF & Adj SS & Adj MS & $F$ value & $P$ value $>F$ \\
\hline Model & 14 & 8818.39 & 629.88 & 9.93 & 0.000 \\
\hline Linear & 4 & 139.42 & 34.85 & 0.55 & 0.703 \\
\hline$A$ & 1 & 0.70 & 0.70 & 0.01 & 0.918 \\
\hline$B$ & 1 & 13.71 & 13.71 & 0.22 & 0.651 \\
\hline C & 1 & 45.25 & 45.25 & 0.71 & 0.416 \\
\hline$D$ & 1 & 79.76 & 79.76 & 1.26 & 0.286 \\
\hline Square & 4 & 8500.90 & 2125.23 & 33.51 & 0.000 \\
\hline$A^{*} A$ & 1 & 1004.21 & 1004.21 & 15.83 & 0.002 \\
\hline$B^{*} B$ & 1 & 692.75 & 692.75 & 10.92 & 0.007 \\
\hline$C^{*} C$ & 1 & 1045.19 & 1045.19 & 16.48 & 0.002 \\
\hline$D^{*} D$ & 1 & 634.72 & 634.72 & 10.01 & 0.009 \\
\hline 2-way interaction & 6 & 178.07 & 29.68 & 0.47 & 0.818 \\
\hline$A^{*} B$ & 1 & 18.53 & 18.53 & 0.29 & 0.600 \\
\hline$A^{*} C$ & 1 & 22.94 & 22.94 & 0.36 & 0.560 \\
\hline$A^{*} D$ & 1 & 27.30 & 27.30 & 0.43 & 0.525 \\
\hline$B^{*} C$ & 1 & 101.51 & 101.51 & 1.60 & 0.232 \\
\hline$B^{*} D$ & 1 & 0.08 & 0.08 & 0.00 & 0.972 \\
\hline$C^{*} D$ & 1 & 7.70 & 7.70 & 0.12 & 0.734 \\
\hline Residual & 11 & 697.60 & 63.42 & & \\
\hline Lack-of-fit & 10 & 697.43 & 69.74 & 414.64 & 0.038 \\
\hline Pure error & 1 & 0.17 & 0.17 & & \\
\hline Total & 25 & 9515.99 & & & \\
\hline
\end{tabular}

$R^{2}=92.67 \% ; R_{\text {adj }}^{2}=90.34 \%$; standard deviation $(\mathrm{SD})=1.83$; coefficient of variation $(\mathrm{CV})=5.85 \%$; adequate precision $(\mathrm{AP})=37.5$ the ratio is decreased to 1 or increased to 3.25 from a center value of 2.125 , less removal was observed. This implies that the more number of $\mathrm{OH}$ radicals are produced in the ratio of 2.125 (Kim et al. 1997) and thereby increasing the removal efficiency, according to the Eq. (1). Hence, $\mathrm{H}_{2} \mathrm{O}_{2}$ / COD ratio of 2.125 was finally considered.

The suitable values $\mathrm{H}_{2} \mathrm{O}_{2} / \mathrm{Fe}^{2+}(B)$ ratios $(5,21,37)$ were considered to enhance the $\mathrm{OH}$ radical production and based on these ratios the dosage of iron (0.09-2.13 mM) and hydrogen peroxide $(5.35-17.4 \mathrm{mM})$ were varied in the treatment process are shown in Tables 2 and 3. Usually, it is seen that, increase in the $\mathrm{H}_{2} \mathrm{O}_{2}$, increases the degradation of pollutants by generating the more hydroxyl radicals (Pignatello 1992). When the hydrogen peroxide dosage was increased from 5.35 to $11.38 \mathrm{mM}$ the dicamba and COD removal was increased up to $84 \%$. Further increase in $\mathrm{H}_{2} \mathrm{O}_{2}$ from 11.38 to $17.4 \mathrm{mM}$ the removal efficiency was decreased shown in Fig. 2a. This was due to, by adding the excess amount of $\mathrm{H}_{2} \mathrm{O}_{2}$ the treatment process was inhibited by decreasing the $\mathrm{OH}$ radical production (scavenging effect) (Masomboon et al. 2009; Zhang et al. 2006). In this process the iron acts as a catalyst, which exploits the rate of reaction and hence the optimization of $\mathrm{Fe}^{2+}$ is as important as $\mathrm{H}_{2} \mathrm{O}_{2}$ (Mijangos et al. 2006). To understand the effect of
$\mathrm{Fe}^{2+}$ on dicamba removal, the dosage of iron was varied from 0.09 to $2.13 \mathrm{mM}$ shown in Fig. 2b. At high iron dose of $0.66 \mathrm{mM}$ (run 12, 19, 20, 22), 1.39 (run 23) and $2.13 \mathrm{mM}$ (run $3,8,16,17)$ less dicamba removal $(<34 \%)$ was achieved and this may due to the fact that, more number of $\mathrm{Fe}^{2+}$ ions scavenged the already produced $\mathrm{OH}$ radicals shown in Eq. (11) (Pignatello 1992). Furthermore, when iron $>0.66 \mathrm{mM}$, sludge formation was observed by forming iron hydroxide complexes and it requires $\mathrm{pH}$ control throughout the reaction to avoid precipitation:

$\mathrm{Fe}^{2+}+\mathrm{OH} \rightarrow \mathrm{Fe}^{3+}+\mathrm{OH}^{-}$.

Suppose, if $\mathrm{Fe}^{2+}$ dosage was decreased to $0.09-0.29 \mathrm{mM}$, only $22-45 \%$ was observed. At a low iron dosage, there is less $\mathrm{Fe}^{2+}$ ions are available to react with oxidant and then the $\mathrm{H}_{2} \mathrm{O}_{2}$ is going to react with already produced $\mathrm{OH}$ radicals to form a $\mathrm{OOH}$ radical shown in Eq. (12) and the formed $\mathrm{OOH}$ radicals were having less oxidation capacity than $\mathrm{OH}$ radicals (Masomboon et al. 2009). Hence the, removal efficiency of dicamba was automatically reduced. Furthermore, in case of run 1, 4, 9 and 13 with $\mathrm{Fe}^{2+}$ dosage of $0.33 \mathrm{mM}$, the significant increase in the dicamba removal of $70-86 \%$ was observed for both responses. Therefore, optimum value iron was considered as 
Table 5 Analysis of variance for $\%$ CODR

\begin{tabular}{|c|c|c|c|c|c|}
\hline Source & DF & Adj SS & Adj MS & $F$ value & $P$ value $>F$ \\
\hline Model & 14 & 8442.98 & 603.07 & 7.57 & 0.001 \\
\hline Linear & 4 & 134.24 & 33.56 & 0.42 & 0.790 \\
\hline$A$ & 1 & 3.51 & 3.51 & 0.04 & 0.838 \\
\hline$B$ & 1 & 41.31 & 41.31 & 0.52 & 0.487 \\
\hline$C$ & 1 & 17.17 & 17.17 & 0.22 & 0.652 \\
\hline$D$ & 1 & 72.24 & 72.24 & 0.91 & 0.362 \\
\hline Square & 4 & 8138.00 & 2034.50 & 25.52 & 0.000 \\
\hline$A^{*} A$ & 1 & 1469.20 & 1469.20 & 18.43 & 0.001 \\
\hline$B^{*} B$ & 1 & 400.91 & 400.91 & 5.03 & 0.046 \\
\hline$C^{*} C$ & 1 & 934.94 & 934.94 & 11.73 & 0.006 \\
\hline$D^{*} D$ & 1 & 696.65 & 696.65 & 8.74 & 0.013 \\
\hline 2-way interaction & 6 & 170.74 & 28.46 & 0.36 & 0.891 \\
\hline$A^{*} B$ & 1 & 3.09 & 3.09 & 0.04 & 0.848 \\
\hline$A^{*} C$ & 1 & 0.20 & 0.20 & 0.00 & 0.961 \\
\hline$A^{*} D$ & 1 & 15.66 & 15.66 & 0.20 & 0.666 \\
\hline$B^{*} C$ & 1 & 69.68 & 69.68 & 0.87 & 0.370 \\
\hline$B^{*} D$ & 1 & 4.81 & 4.81 & 0.06 & 0.811 \\
\hline$C^{*} D$ & 1 & 77.31 & 77.31 & 0.97 & 0.346 \\
\hline Residual & 11 & 876.85 & 79.71 & & \\
\hline Lack-of-fit & 10 & 876.46 & 87.65 & 226.36 & 0.052 \\
\hline Pure error & 1 & 0.39 & 0.39 & & \\
\hline Total & 25 & 9319.82 & & & \\
\hline
\end{tabular}

$R^{2}=90.59 \% ; R_{\text {adj }}^{2}=88.62 \% ;$ standard deviation $(\mathrm{SD})=2.06 ;$ coefficient of variation $(\mathrm{CV})=6.91 \%$; adequate precision $(\mathrm{AP})=61.7$
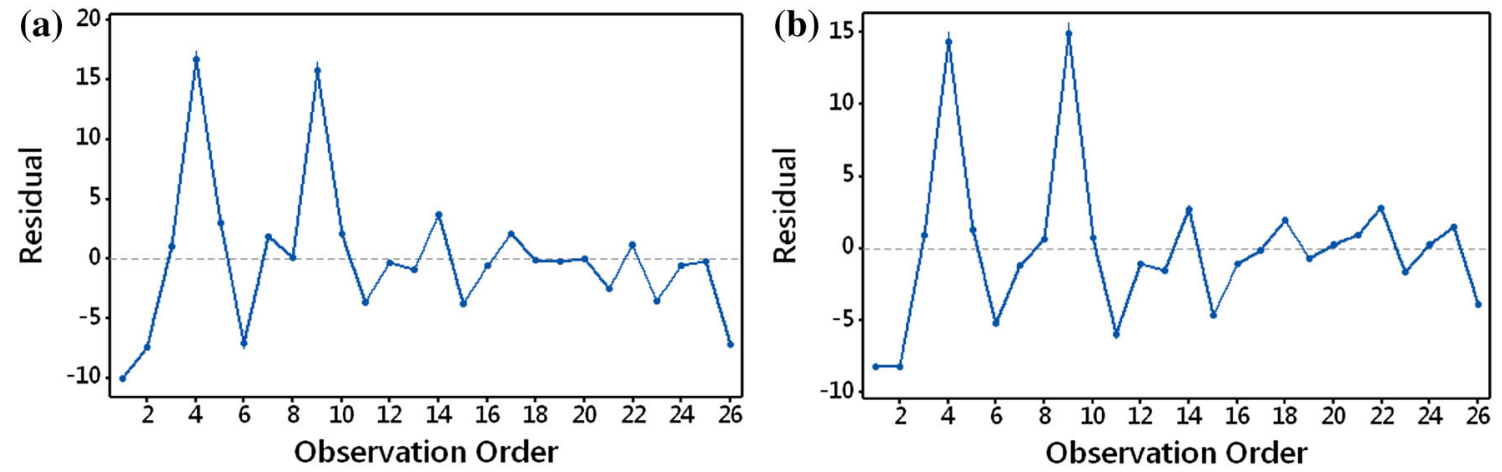

Fig. 1 Residual plots vs. Total number of runs a \% COD removal efficiency, b \% dicamba removal efficiency

$0.33 \mathrm{mM}$. In case of run 6 and 15 with $\mathrm{pH} 2$ and 5, the less dicamba removal was achieved even though $\mathrm{Fe}^{2+}$ dosage was $0.33 \mathrm{mM}$, this implies that the $\mathrm{pH}$ is also influencing on the removal efficiency. Therefore conclusively, when $\mathrm{H}_{2} \mathrm{O}_{2} /$ $\mathrm{Fe}^{2+}$ ratio was 5 and 37, with a pH 5 and 2, the less removal was achieved and with $\mathrm{H}_{2} \mathrm{O}_{2} / \mathrm{Fe}^{2+}$ ratio of 21 and $\mathrm{pH} 3.5$ the significant removal was achieved:

$\mathrm{H}_{2} \mathrm{O}_{2}+\mathrm{OH} \rightarrow \mathrm{H}_{2} \mathrm{O}+\mathrm{OOH}$.

The Fenton's process is largely influenced by the $\mathrm{pH}$ of the solution and literature says that, it works in the acidic range from 2 to 4 (Masomboon et al. 2009). Hence, in this work the $\mathrm{pH}$ varied from 2 to 5 with 3.5 as a center value. From the Table 3, it is seen that, when the $\mathrm{pH}$ is at 2 and 5 , the slow degradation of $22-46 \%$ was achieved. However, in case of runs 1, 4, 9 and 13 the higher removal was observed at $\mathrm{pH} 3.5$. At $\mathrm{pH}>3.5$, the deactivation of a $\mathrm{Fe}^{2+}$ ions by forming ferric hydroxide complexes was observed and thereby suppressing generation of $\mathrm{OH}$ radicals (Lucas and Peres 2006). At lower $\mathrm{pH}(<3.5)$, may be the scavenging $\mathrm{OH}$ radicals by $\mathrm{H}^{+}$ions was observed, which leads to the lesser degradation rate shown in Eq. (13) 

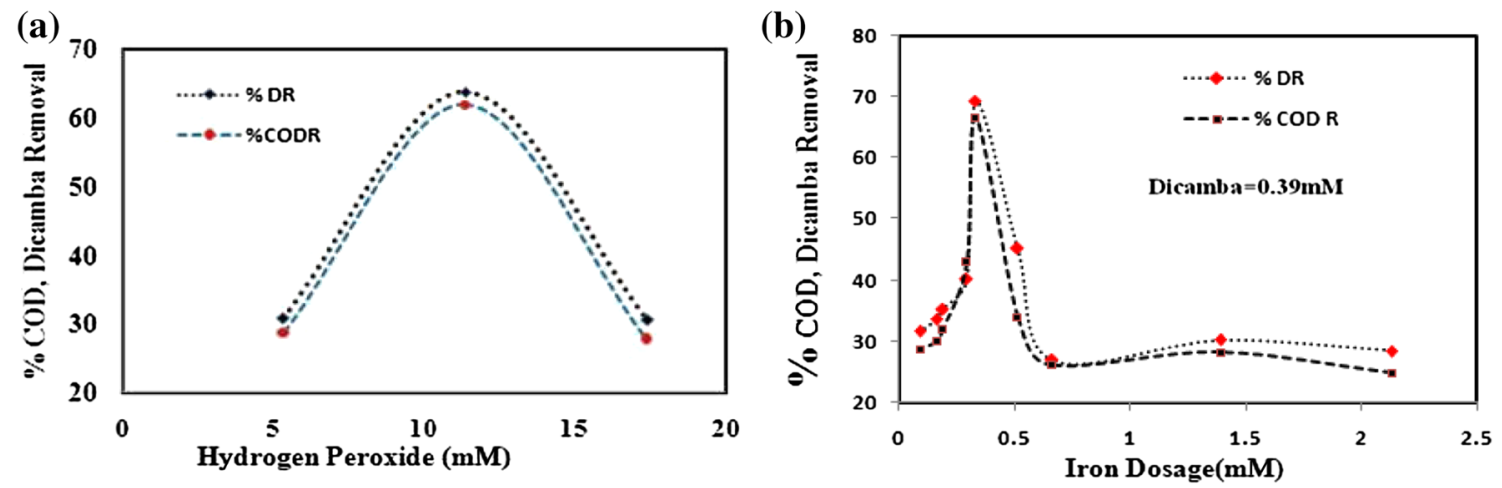

Fig. 2 a Effect of $\mathrm{H}_{2} \mathrm{O}_{2}$ on \% COD and dicamba removal efficiency. b Effect of $\mathrm{Fe}^{2+}$ on \% COD and dicamba removal efficiency

(a)

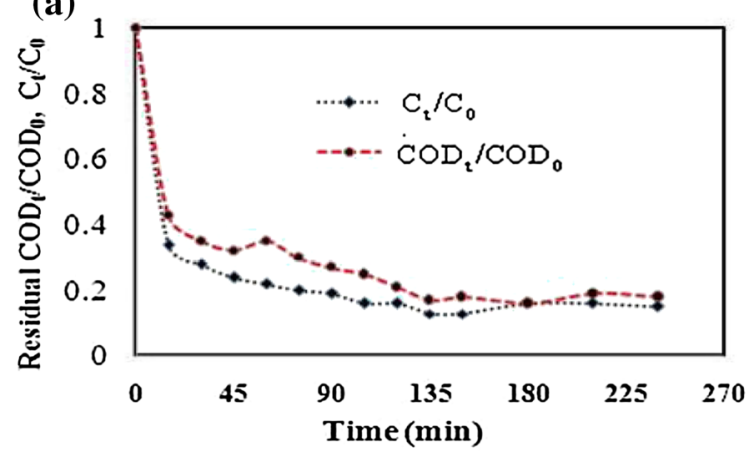

Fig. 3 a Residual $\mathrm{COD}_{t} / \mathrm{COD}_{0}$ and $\mathrm{C}_{t} / \mathrm{C}_{0}$ with reaction time, where $\mathrm{COD}_{t}=$ final $\mathrm{COD}$ at time $t \mathrm{~min} ; \mathrm{COD}_{0}=$ initial $\mathrm{COD}$ at time $0 \mathrm{~min} ; C_{t}=$ final concentration at time $t \mathrm{~min} ; C_{0}=$ initial

(Martins et al. 2010). It was also said from the literature (Oliveira et al. 2006), at $\mathrm{pH}<3$, production of Oxonium ions were observed, which makes the oxidant less reactive. Hence, the optimum $\mathrm{pH}$ of 3.5 was maintained in an aqueous medium to get maximum removal efficiency:

$\mathrm{Fe}^{3+}+\mathrm{H}_{2} \mathrm{O}_{2} \rightarrow \mathrm{Fe}^{2+}+\mathrm{H}^{+}+\mathrm{HO}_{2}$.

The reaction time $(D)$ is also an important factor and was varied from 30 to $240 \mathrm{~min}$. It had a significant influence in generating the $\mathrm{OH}$ radicals. In case of run 1 at $30 \mathrm{~min}$, the reaction was faster and $70-74 \%$ of degradation was achieved. Furthermore, in case of runs 4,9 and 13 with same experimental conditions $\left(\mathrm{pH}=3.5, \quad \mathrm{Fe}^{2+}=0.25 \mathrm{mM}\right.$, $\mathrm{H}_{2} \mathrm{O}_{2}=11.38 \mathrm{mM}$ ), the reaction rate was slowly increased from 70 to $85 \%$. This implies that at $30 \mathrm{~min}$, more $\mathrm{OH}$ radicals are generated (Eq. 1) and accordingly the degradation rate was also faster and after $30 \mathrm{~min}$ the hydroperoxyl radicals $\left(\mathrm{HO}_{2}\right)$ were produced (Eqs. 14, 15). However, in case of the runs $(3,5,12,14,17,22,24$, and 25$)$ at $30 \mathrm{~min}$, less removal of $20-36 \%$ was achieved. This implies that the factors $A, B$ and $C$ are also influencing in the removal efficiency. To know the degradation rate at every $15 \mathrm{~min}$, the kinetic studies were (b)

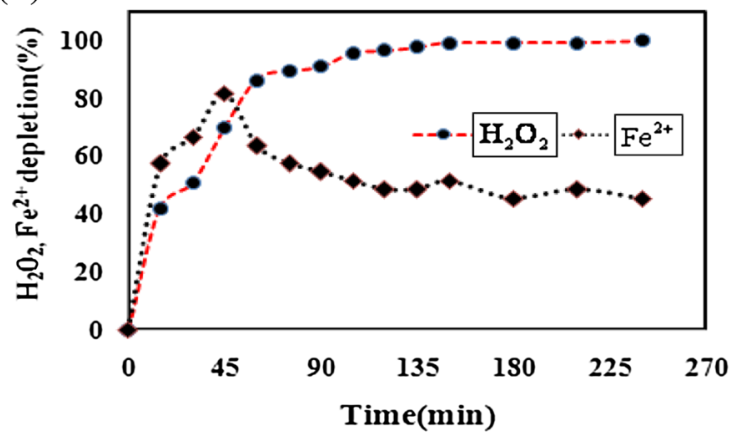

concentration at time 0 min. b $\% \mathrm{H}_{2} \mathrm{O}_{2}$ and $\mathrm{Fe}^{2+}$ depletion with time. $\mathrm{H}_{2} \mathrm{O}_{2}=11.38 \mathrm{mM} ; \quad \mathrm{Fe}^{2+}=0.25 \mathrm{mM} ; \quad \mathrm{COD}_{0}=182 \mathrm{ppm}$, $C_{0}=0.39 \mathrm{mM}, \mathrm{pH}=3.5$

carried at optimum Fenton's dosage $\left(\mathrm{Fe}^{2+}=0.25 \mathrm{mM}\right.$, $\mathrm{H}_{2} \mathrm{O}_{2}=11.38 \mathrm{mM}$ and $\mathrm{pH}=3.5$ ) shown in Fig. $3 \mathrm{a}$ and it was observed that after $135 \mathrm{~min}$, removal rate was constant. Hence, finally optimum reaction time of $135 \mathrm{~min}$ was considered. The $\mathrm{H}_{2} \mathrm{O}_{2}$ and $\mathrm{Fe}^{2+}$ depletion was also monitored through the treatment process shown in Fig. 3b, it is seen that $100 \%$ decomposition of $\mathrm{H}_{2} \mathrm{O}_{2}$ was observed within $240 \mathrm{~min}$ (run 13) and $98 \%$ consumption at $\mathrm{H}_{2} \mathrm{O}_{2}$ at run 9. However, from 0 to $45 \min 81 \%$ of $\mathrm{Fe}^{2+}$ was converted to $\mathrm{Fe}^{3+}$, then after that slowly the $\mathrm{Fe}^{2+}$ regeneration was observed in optimum conditions and thereby achieving the maximum degradation rate in the treatment process. The similar results were reported in other research also (Colombo et al. 2013). Finally, from the Fig. $4 a, b$ the optimum values are confirmed as $2.125,21,3.5$ and 135 for $A, B, C$ and $D$ respectively. From the Table 3 and Fig. $5 \mathrm{a}$, b, it was concluded that the actual experimental and predicted values are similar in nature and the data points are distributed along the straight line, it implies that better results are achieved:

$\mathrm{H}_{2} \mathrm{O}_{2}+\mathrm{Fe}^{3+} \rightarrow \mathrm{H}^{+}+\mathrm{FeOOH}^{2+}$,

$\mathrm{FeOOH}^{2+} \rightarrow \mathrm{HO}_{2}+\mathrm{Fe}^{2+}$. 

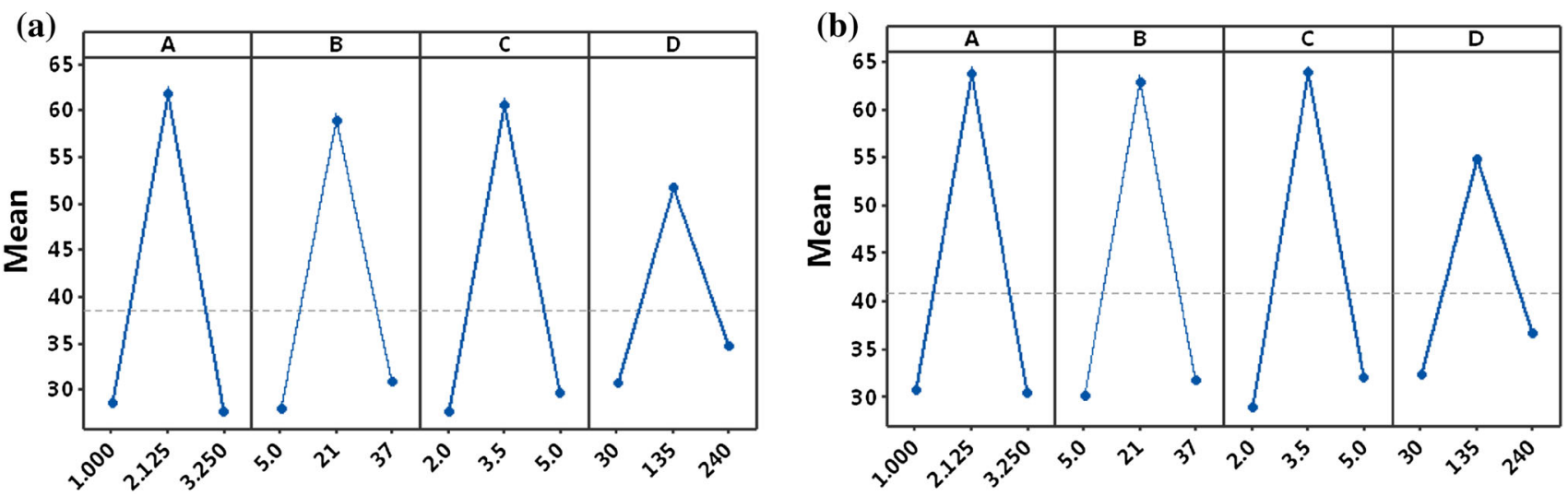

Fig. 4 Main effects plots for both responses a \% COD removal efficiency, b \% dicamba removal efficiency
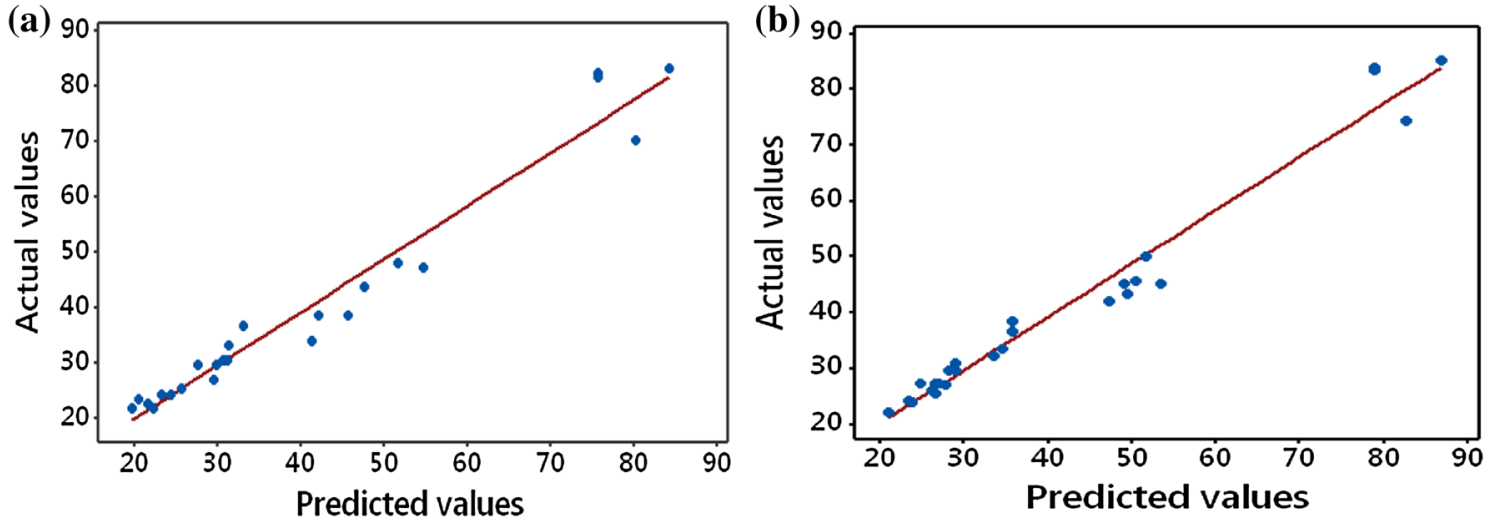

Fig. 5 Plot of predicted versus actual values for both responses a $\%$ COD removal efficiency, b $\%$ dicamba removal efficiency

\section{Degradation products (HPLC-MS analysis)}

The decay of dicamba was analyzed after Fenton's treatment process and the release of chloride with time was monitored shown in Fig. 6. Before and after treatment the dicamba was eluted at same retention time (1.4 min), however, there was a relatively small peak was observed at the end of reaction time (240 $\mathrm{min}$ ). It clearly says that, after treatment a small portion of dicamba was retained in the treatment process. The $82 \%$ of the dicamba was degraded and finally it was mineralized to oxalic acid, chloride, $\mathrm{CO}_{2}$ and $\mathrm{H}_{2} \mathrm{O}$. The \% dicamba removal was calculated with the help of the calibration curve (Supplementary material 1). This was confirmed with LCMS mass table (Supplementary material 2 ) having highest $\mathrm{m} / \mathrm{z}$ value of 90 (oxalic acid), in comparison with NIST library and the peak at a $m / z$ value of $223(M+2)$ corresponds to residual dicamba in the reactor. Also, this mineralization process was confirmed with COD removal. The release of chloride ion was faster $(31 \mathrm{mg} / \mathrm{L})$ at the initial stage $(0-15 \mathrm{~min})$, then it slowly increased up to $64.7 \mathrm{mg} / \mathrm{L}$ till $135 \mathrm{~min}$ and after that no increase in the chloride concentration was observed. The similar kind of results was observed in the other literature
(Brillas et al. 2003) and the mineralization process can be written with the following Eq. (16):

$\mathrm{C}_{8} \mathrm{H}_{6} \mathrm{Cl}_{2} \mathrm{O}_{3}+\mathrm{OH} \rightarrow$ Oxalic acid $+\mathrm{Cl}^{-}+\mathrm{H}_{2} \mathrm{O}+\mathrm{CO}_{2}$.

\section{Contour overlay plot for validation}

To find out the optimum region or working feasible region for Fenton's process, the contour plots were overlaid graphically, where all the variables meet simultaneously in a particular area (Ahmad et al. 2005). In this optimization process the desired goal was to maximize the both responses and therefore, the boundary values were defined as $Y_{1}(21.75,81.53)$ and $Y_{2}(22.3,84.01)$ with $\mathrm{H}_{2} \mathrm{O}_{2} / \mathrm{Fe}^{2+}$ (B) ratio of 21 . The reaction time was considered as $135 \mathrm{~min}$ instead of $240 \mathrm{~min}$, as there is less difference in the removal efficiency $(<2 \%)$ was observed. Figure 7 shows the overlay plot and the total area is divided into three regions, which are separated by circular dotted lines. The shaded portion consists of two regions, in which the middle area is not feasible for both COD and dicamba removal efficiencies (NFRCD) and other region is feasible 


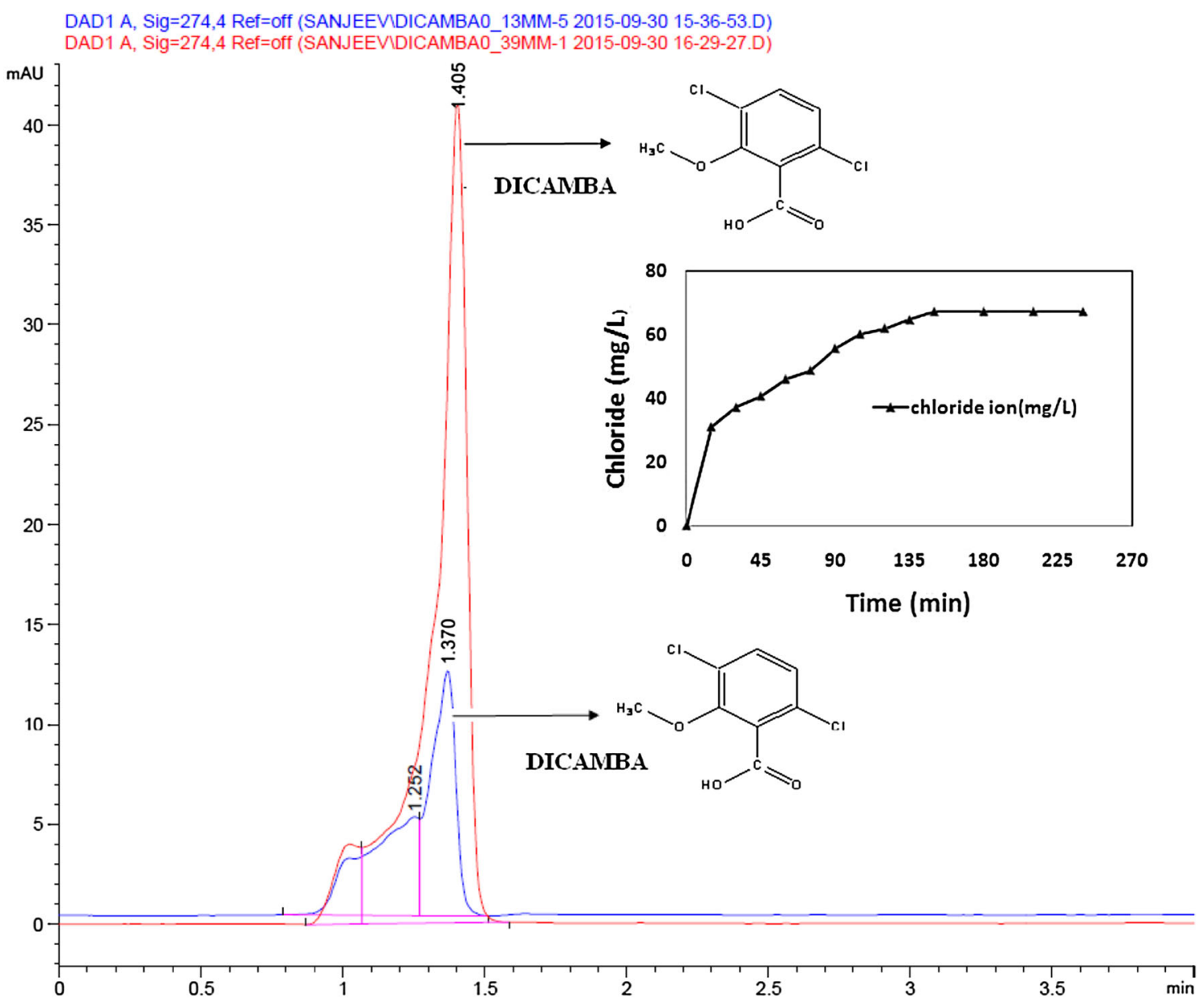

Fig. 6 HPLC along with LCMS analysis

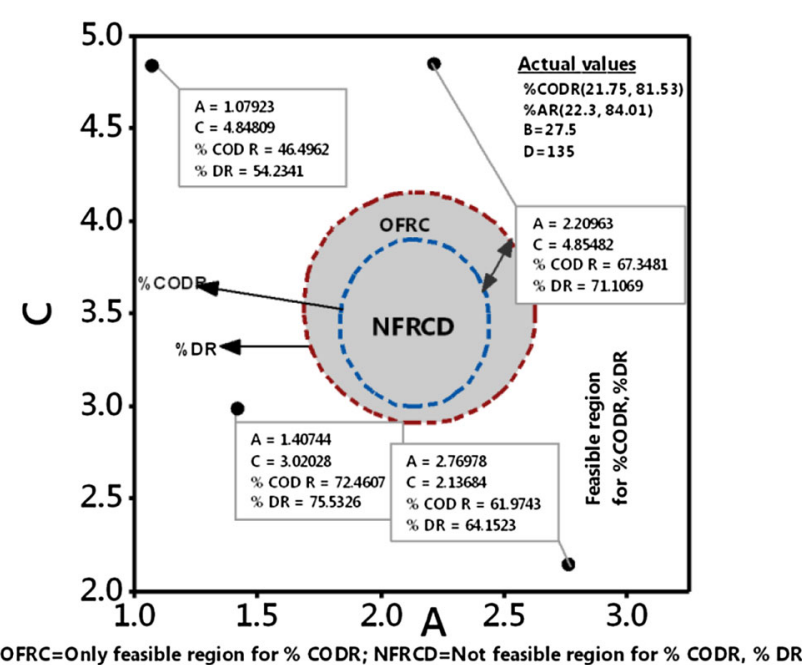

Fig. 7 Contour overlay plot

for only COD removal efficiency $\left(Y_{1}\right)$. The remaining unshaded area is suitable for both responses and it was considered as an optimum region.
To verify the results obtained in Table 3 , four sets of additional laboratory experiments (runs 27, 28, 29 and 30) were performed suggested by overlay plot from unshaded region. The experimental conditions are tagged in Fig. 7 and the results along with statistical analysis were shown in Table 6. The standard deviation, coefficient of variation and adequate precision were $<4 \%,<8$ and $>12$ respectively. These values are within the prescribed standard limits discussed in the literatures (Beg et al. 2003; Zinatizadeh et al. 2006). This implies that, the additional experiments confirm the all 26 experiments results and hence the responses surface methodology can be successfully applied for design of experiments in Fenton's process.

\section{Conclusions}

Based on the present research work results and discussions the following conclusions were drawn.

- The maximum removal efficiencies of $85.33 \%$ (dicamba removal) and $83.29 \%$ (COD removal) were 
Table 6 Optimization of additional experiments

\begin{tabular}{|c|c|c|c|c|c|c|c|c|c|c|c|c|c|c|c|c|}
\hline \multirow[t]{2}{*}{ Run } & \multicolumn{4}{|c|}{ Independent factors } & \multicolumn{2}{|c|}{$\%$ CODR } & \multicolumn{2}{|l|}{$\% \mathrm{AR}$} & \multicolumn{2}{|l|}{ Error } & \multicolumn{2}{|l|}{ SD } & \multicolumn{2}{|l|}{$\mathrm{CV}$} & \multicolumn{2}{|l|}{ AP } \\
\hline & $A$ & $B$ & $C$ & $D$ & Ac & $\operatorname{Pr}$ & Ac & $\operatorname{Pr}$ & $\%$ CODR & $\%$ DR & $\%$ CODR & $\% \mathrm{DR}$ & $\%$ CODR & $\% \mathrm{DR}$ & $\%$ CODR & $\% \mathrm{DR}$ \\
\hline 27 & 1.08 & 21 & 4.85 & 135 & 43.7 & 46.5 & 50.3 & 54.5 & 2.76 & 4.21 & 1.95 & 2.98 & 6.12 & 8.03 & 16.85 & 12.95 \\
\hline 28 & 2.21 & 21 & 4.85 & 135 & 62.2 & 67.3 & 68.1 & 71.1 & 5.16 & 3.02 & 3.65 & 2.14 & 7.97 & 4.34 & 13.05 & 23.55 \\
\hline 29 & 1.41 & 21 & 3.02 & 135 & 70.9 & 72.4 & 73.1 & 75.5 & 1.47 & 2.37 & 1.04 & 1.68 & 2.05 & 3.19 & 49.29 & 31.87 \\
\hline 30 & 2.77 & 21 & 2.14 & 135 & 58.6 & 61.97 & 62.13 & 64.15 & 3.29 & 2.02 & 2.33 & 1.43 & 5.45 & 3.2 & 18.84 & 31.76 \\
\hline
\end{tabular}

$\% C O D R \%$ COD removal, \% DR \% dicamba removal, $S D$ standard deviation, $C V$ coefficient of variation, $A P$ adequate precision, $A c$ actual values, $\operatorname{Pr}$ predicted values

achieved with the optimum values of $2.125,21,3.5$ and 135 min for $\mathrm{H}_{2} \mathrm{O}_{2} / \mathrm{COD}, \mathrm{H}_{2} \mathrm{O}_{2} / \mathrm{Fe}^{2+}$, $\mathrm{pH}$ and reaction time respectively.

- The optimum dosage of $\mathrm{H}_{2} \mathrm{O}_{2}$ and $\mathrm{Fe}^{2+}$ were found to be 11.38 and $0.33 \mathrm{mM}$ respectively.

- From the regression analysis, it was found that the $R^{2}$ and $R_{\text {adj }}^{2}$ values for both the responses were close to each other and the standard deviation $(<4 \%)$, coefficient of variation $(<8), F$ value $(>2.74)$ and adequate precision $(>12)$ were within the prescribed limits.

- The LC/MS analysis confirms that, $82 \%$ of the dicamba was of mineralized to oxalic acid, chloride ion, $\mathrm{CO}_{2}$, and $\mathrm{H}_{2} \mathrm{O}$.

- The overlay plot results prove that the additional experiments were also showing similar results with predicted values and hence, the Fenton's process is recommended for degradation of dicamba in aqueous medium.

Open Access This article is distributed under the terms of the Creative Commons Attribution 4.0 International License (http:// creativecommons.org/licenses/by/4.0/), which permits unrestricted use, distribution, and reproduction in any medium, provided you give appropriate credit to the original author(s) and the source, provide a link to the Creative Commons license, and indicate if changes were made.

\section{References}

Ahmad AL, Ismail S, Bhatia S (2005) Optimization of coagulationflocculation process for palm oil mill effluent using response surface methodology. Environ Sci Technol 39:2828-2834

Ahmadi M, Vahabzadeh F, Bonakdarpour B, Mofarrah E, Mehranian M (2005) Application of the central composite design and response surface methodology to the advanced treatment of olive oil processing wastewater using Fenton's peroxidation. J Hazard Mater 123(1-3):187-195. doi:10.1016/j.jhazmat.2005.03.042

American Public Health Association (APHA), Federation WE, APH Association (2005) Standard methods for the examination of water and wastewater. Washington DC, USA

Bach A, Shemer H, Semiat R (2010) Kinetics of phenol mineralization by Fenton-like oxidation. Desalination 264:188-192

Bashir MJK, Isa MH, Kutty SR, Awang ZB, Aziz HA, Mohajeri S, Farooqi IH (2009) Landfill leachate treatment by electrochemical oxidation. Waste Manag 29(9):2534-2541
Beg Q, Sahai V, Gupta R (2003) Statistical media optimization and alkaline protease production from Bacillus mojavensis in a bioreactor. Process Biochem 39:203-209

Box GEP, Behnken DW (1960) Some new three level designs for the study of quantitative variable. Technometrics 2:455-475

Box GEP, Wilson KB (1951) On the experimental attainment of optimum conditions. J R Stat Soc Ser B 13:1-45

Brillas E, Banos MA, Garrido JA (2003) Mineralization of herbicide 3,6-dichloro-2-methoxybenzoic acid in aqueous medium by anodic oxidation, electro-Fenton and photoelectro-Fenton process. Electrochim Acta 48:1697-1705

Catalkaya EC, Kargi F (2009) Degradation and mineralization of simazine in aqueous solution by zone/hydrogen peroxide advanced oxidation. J Environ Eng 135:1357-1364

Chu L, Wang J, Dong J, Liu H, Sun X (2012) Treatment of coking wastewater by an advanced Fenton oxidation process using iron powder and hydrogen peroxide. Chemosphere 86(4):409-414

Colombo R, Ferreira TCR, Alves SA, Carneiro RL, Lanza MRV (2013) Application of the response surface and desirability design to the Lambda-cyhalothrin degradation using photoFenton reaction. J Environ Manag 118:32-39

García-Ǵomez C, Vidales-Contreras JA, Nápoles-Armenta J, Gortáres-Moroyoqui P (2016) Optimization of phenol removal using $\mathrm{Ti} / \mathrm{PbO}_{2}$ anode with response surface methodology. J Environ Eng 142(4):04016004

Ghoshdastidar AJ, Tong AZ (2013) Treatment of 2,4-D, mecoprop, and dicamba using membrane bioreactor technology. Environ Sci Pollut Res 20:5188-5197. doi:10.1007/s11356-013-1498-z

González NV, Soloneski SE, Larramendy ML (2006) Genotoxicity analysis of the phenoxy herbicide dicamba in mammalian cells in vitro. Toxicol In Vitro 20:1481-1487

Hamilton DJ, Ambrus Á, Dieterle RM, Felsot AS, Harris CA, Holland PT, Katayama A, Kurihara N, Linders J, Unsworth J, Wong SS (2003) Regulatory limits for pesticide residues in water. Pure Appl Chem 75:1123-1155

Hasan DUB, Abdul Aziz AR, Daud WMAW (2012) Oxidative mineralisation of petroleum refinery effluent using Fenton-like process. Chem Eng Res Des 90(2):298-307. doi:10.1016/j.cherd. 2011.06.010

Im J-K, Cho I-H, Kim S-K, Zoh K-D (2012) Optimization of carbamazepine removal in $\mathrm{O}_{3} / \mathrm{UV} / \mathrm{H}_{2} \mathrm{O}_{2}$ system using a response surface methodology with central composite design. Desalination 285:306-314

Jiang L, Huang J, Liang L, Zheng YP, Yang H (2008) Mobility of prometryne in soil as affected by dissolved organic matter. J Agric Food Chem 56:11933-11940

Joglekar AM, May AT (1987) Product excellence through design of experiments. Cereal Foods World 32(12):857-868

Kavitha V, Palanivelu K (2004) The role of ferrous ion in Fenton and photo-Fenton processes for the degradation of phenol. Chemosphere 55(9):1235-1243

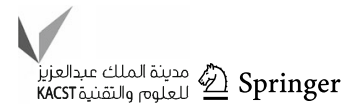


Kim S, Geissen S, Vogelpohl A (1997) Landfill leachate treatment by a photoassisted Fenton reaction. Water Sci Technol 35:239-248

Li H, Zhou S, Sun Y, Lv J (2010) Application of response surface methodology to the advanced treatment of biologically stabilized landfill leachate using Fenton's reagent. Waste Manag 30:2122-2129

Lu M-C, Chen J-N (1997) Pretreatment of pesticide wastewater by photocatalytic oxidation. Water Sci Technol 36(2-3):117-122. doi:10.1016/s0273-1223(97)00377-6

Lucas MS, Peres JA (2006) Decolorization of the azo dye reactive black 5 by Fenton and photo-Fenton oxidation. Dyes Pigm 71:236-244

Lucas MS, Dias AA, Sampaio A, Amaral C, Peres JA (2007) Degradation of a textile reactive Azo dye by a combined chemicalbiological process: Fenton's reagent-yeast. Water Res 41(5):1103-1109

Manu B, Mahamood S (2011) Enhanced degradation of paracetamol by UV-C supported photo-Fenton process over Fenton oxidation. Water Sci Technol 64(12):2433-2438

Martins RC, Rossi AF, Quinta-Ferreira RM (2010) Fenton's oxidation process for phenolic wastewater remediation and biodegradability enhancement. J Hazard Mater 180:716-721

Masomboon N, Ratanatamskul C, Lu M (2009) Chemical oxidation of 2,6-imethylaniline in the Fenton process. Environ Sci Technol 43:8629-8634

Masomboon N, Chen C-W, Anotai J, Lu M-C (2010) A statistical experimental design to determine o-toluidine degradation by the photo-Fenton process. Chem Eng J 159:116-122

Mater L, Rosa EVC, Berto J, Corrêa AXR, Schwingel PR, Radetski CM (2007) A simple methodology to evaluate influence of $\mathrm{H}_{2} \mathrm{O}_{2}$ and $\mathrm{Fe}^{2+}$ concentrations on the mineralization and biodegradability of organic compounds in water and soil contaminated with crude petroleum. J Hazard Mater 149:379-386

Maya-Treviñoa ML, Guzmán-Mara JL, Hinojosa-Reyesa L, RamosDelgadoa NA, Maldonadob MI, Hernández-Ramíreza A (2014) Activity-of-the- $\mathrm{ZnO}-\mathrm{Fe}_{2} \mathrm{O}_{3}$-catalyst-on-the-degradation-of-Dicamba-and-2-4-D-herbicides-using-simulated-solar-light. Ceram Int 40:8701-8708

Mijangos F, Varona F, Villota N (2006) Changes in solution color during phenol oxidation by Fenton reagent. Environ Sci Technol 40(17):5538-5543

Myers R, Montgomery D (2002) Response surface methodology: process and product optimization using designed experiments, 2nd edn. Wiley, New York

Nitschke L, Wilk A, Schüssler W, Metzner G, Lind G (1999) Biodegradation in laboratory activated sludge plants and aquatic toxicity of herbicides. Chemosphere 39(13):2313-2323. doi:10. 1016/s0045-6535(99)00140-x

Oliveira R, Almeida M, Santos L, Madeira L (2006) Experimental design of 2,4-dichlorophenol oxidation by Fenton's reaction. Ind Eng Chem Res 45:1266-1276
Pignatello JJ (1992) Dark and photoassisted $\mathrm{Fe}^{3+}$ Catalyzed degradation of chlorophenoxy herbicides by hydrogen peroxide. Environ Sci Technol 26:944-951

Saber A, Hasheminejad H, Taebi A, Ghaffari G (2014) Optimization of Fenton-based treatment of petroleum refinery wastewater with scrap iron using response surface methodology. Appl Water Sci 4:283-290

Santos SCR, Boaventura RAR (2008) Adsorption modelling of textile dyes by sepiolite, ppl. Clay Sci 42:137-145

Shin E-H, Choi J-H, Abd El-Aty AM, Khay S, Kim S-J, Im MH, Kwon C-H, Shim J-H (2011) Simultaneous determination of three acidic herbicide residues in food crops using HPLC and confirmation via LC-MS/MS. Biomed Chromatogr 25:124-135

Tiwari BK, Muthukumarappan K, O’Donnell CP, Cullen PJ (2008) Modelling colour degradation of orange juice by ozone treatment using response surface methodology. J Food Eng 88(4):553-560

Torrades F, Saiz S, Garcia-Hortal JA (2011) Using central composite experimental design to optimize the degradation of black liquor by Fenton reagent. Desalination 268:97-102

Wang QQ, Lemley AT (2001) Kinetic model and optimization of 2,4D degradation by anodic Fenton treatment. Environ Sci Technol 35:4509-4514

Wang QQ, Lemley AT (2003) Oxidative degradation and detoxification of aqueous carbofuran by membrane anodic Fenton treatment. J Hazard Mater B98:241-255

Wu T, Englehardt JD (2012) A New method for removal of hydrogen peroxidei interference in the analysis of chemical oxygen demand. Environ Sci Technol 46:2291-2298

Xu X-R, Li H-B, Wang W-H, Gu J-D (2004) Degradation of dyes in aqueous solutions by the Fenton process. Chemosphere 57:595-600

You Y, Zhao H, Vance GF (2002) Adsorption of dicamba (3,6dichloro-2-methoxy benzoic acid) in aqueous solution by calcined-layered double hydroxide. Appl Clay Sci 21:217-226

Zhang H, Zhang DB, Zhou JY (2006) Removal of COD from landfill leachate by electro-Fenton method. J Hazard Mater 135(1-3):106-111

Zhang H, Choi HJ, Canazo P, Huang CP (2009) Multivariate approach to the Fenton process for the treatment of landfill leachate. J Hazard Mater 161:1306-1312

Zhang H, Li YL, Wu XG, Zhang YJ, Zhang DB (2010) Application of response surface methodology to the treatment landfill leachate in a three-dimensional electrochemical reactor. Waste Manag 30(11):2096-2102

Zhang H, Li Y, Wu X (2012) Statistical experiment design approach for the treatment of landfill leachate by photoelectro-Fenton process. J Environ Eng 138(3):278-285

Zinatizadeh AAL, Mohamed AR, Abdullah AZ, Mashitah MD, Hasnain Isa M, Najafpour GD (2006) Process modeling and analysis of palm oil mill effluent treatment in an up-flow anaerobic sludge mixed film bioreactor using response surface methodology (RSM). Water Res 40:3193-3208 